\title{
Facebook and Diagnosis of Depression: A Mixed Methods Study
}

\author{
Jason L. Skues, Robert F. Banagan, Lisa Z. Wise \\ Department of Psychological Sciences and Statistics, Swinburne University of Technology, Melbourne, \\ Australia \\ Email: jskues@swin.edu.au
}

Received 3 May 2014; revised 5 June 2014; accepted 2 July 2014

Copyright $@ 2014$ by authors and Scientific Research Publishing Inc.

This work is licensed under the Creative Commons Attribution International License (CC BY).

http://creativecommons.org/licenses/by/4.0/

(c) () Open Access

\begin{abstract}
A mixed-methods research design was employed to investigate the association between depression and Facebook use. An online questionnaire was completed by 135 participants from a medium-sized Australian university. Follow-up semi-structured interviews were conducted with 4 of 10 participants who volunteered to be interviewed. Although $25 \%$ of students were identified as at-risk for depression, quantitative analyses revealed no significant differences in Facebook use for at-risk versus not at-risk participants. None of the 5 at-risk students who volunteered to be interviewed actually responded to repeated attempts to make an interview time, whereas 4/5 not-at-risk students were interviewed. Notably, discrepancies in Facebook use reported in selfreport questionnaire and interview data were revealed, which have implications for researchers when interpreting self-report Facebook usage data.
\end{abstract}

\section{Keywords}

Assessment, Depression, Facebook, Mediated Communication, Mixed-Methods

\section{Introduction}

Depression is one of the most common health issues impacting university students, with prevalence rates having increased substantially in this population over the past few years [1] [2]. In particular, several studies have reported prevalence rates of between 10 and 25 percent across different cultures [3]-[9]. Depression has been associated with poor academic performance [10] [11], disengagement and eventual dropout from education [12], other health-related concerns [13], self-injury [14] and suicide [11] [15]. Based on prevalence studies, depression in the university student population is frequently undiagnosed due to the requirement for the individual visit a clinic to seek diagnosis and assistance. 
Over 90 percent of typical university students have Facebook accounts [16] [17], with students spending, on average, 60 minutes per day on Facebook. Despite numerous studies investigating psychological factors such as personality traits [18]-[22], self-esteem [18] [22]-[25], loneliness [18] [26], and narcissism [25] [27] and how these factors are related to Facebook, a limitation in the literature is that there have been few studies [28]-[31] examining the association between depression and Facebook use. Rosen et al. (2013) tested whether Facebook use was associated with personality and mood disorders among a large sample of adult participants using an assessment tool that provides information on the clinical symptoms of psychological disorders. They found that general Facebook use and number of Facebook friends was not associated with major depression, but number of friends was negatively associated with dysthymia where adults with more friends tended to have lower levels of dysthymia.

One mode of communication regularly employed by Facebook users is posting status updates, which are broadcasts that reflect what an individual may be thinking or feeling at the time. Given that students provide insight into their thoughts and feelings via Facebook status updates, it may be possible to identify and help students who may be suffering undiagnosed depressive disorders to access appropriate support. Moreno and colleagues (2011) examined 200 college students' disclosures on Facebook and reported that 25 percent of students displayed depressive symptoms on their Facebook profiles, with 2.5 percent satisfying the proxy criteria for a major depressive episode according to the Diagnostic and Statistical Manual of Mental Disorders criteria [32]. In a further study and the first to demonstrate an association between self-reported depression and content displayed on Facebook, Moreno et al. (2012) found in a sample of 215 university students that one-third of students displayed depressive symptoms on Facebook, with displayed depression references significantly associated with self-reported depression scores. The most common proxy symptom was reference to a depressed mood, followed by feelings of guilt and worthlessness. According to Moreno et al., how university students use Facebook (e.g., status updates, Facebook activity) may provide researchers and mental health professionals with some insight into aspects of students' mental health that may not be apparent in their offline behaviour.

Although some studies have coded Facebook profiles, few studies have utilised interviews or mixed methods to investigate Facebook, despite the fact that single data collection methods such as administering a self-report questionnaire do not permit an in-depth and detailed understanding of the actual lived experience of the participant [31]. Hence, there is a need for researchers to utilise both quantitative and qualitative research methods when investigating how people use Facebook.

The purpose of this study was to investigate the association between depression and Facebook use among a sample of Australian university students using a mixed methods approach (e.g., self-report questionnaire and interviews). Two research questions were formulated and tested:

1) How do university students use Facebook?

2) Are there differences in patterns of Facebook use for students identified as at-risk versus not at-risk for depression?

\section{Method}

\subsection{Participants}

The participants were undergraduate students from a Melbourne metropolitan university. One hundred and fiftyfour students participated in the study. Of these, 96 percent had Facebook accounts. However, participants' data were not included in the analyses if they had more than 10 percent missing data [33]. The final sample comprised 92 women and 40 men with an average age of 20.43 years $(S D=5.26)$. Three participants did not specify their sex.

\subsection{Materials}

The scales administered in the current study included measures of Facebook use and depression. These were delivered online using Opinio online survey software package [34].

The Facebook Questionnaire (FQ) [20] is a 28-item questionnaire designed to measure basic Facebook use, attitudes towards Facebook and information relating to the posting of personal information. The basic use items were administered to measure time spent using Facebook, number of Facebook friends, preferred functions (e.g., wall, messages) and reasons for using Facebook (e.g., to communicate with friends). 
The Depression and Anxiety Stress Scale (DASS) [35] is a 42-item measure of negative emotional states, including depression which has been found to be a reliable and valid measure of depression for both clinical and community samples. Participants report on a four-point Likert scale from 0 (Strongly Disagree) to 3 (Strongly Agree) the extent to which they have experienced each symptom over a specified time period. Scores from the relevant responses were summed to produce a depression score with higher scores representing more depression. Depression scores can be classified into different categories where 0 to 9 is the Normal Range; 10 to 13 is the Mild Range; 14 to 20 is the Moderate Range, 21 to 27 is the Severe Range and 28+ scores are in the Extremely Severe Range. For this study, participants who reported depression scores in the Severe and Extremely Severe categories were deemed to be "at-risk", which is consistent with the approach used in other studies [5]. Cronbach's alpha for the DASS was 0.90 .

\subsection{Procedure}

Ethics approval for the current research was obtained from the university’s Human Research Ethics Committee. Participants completed the survey during the semester at a location and time of their choosing. Participation in the research was on a voluntary basis with return of a completed online questionnaire taken as consent to participate. At the conclusion of the online questionnaire, participants were offered the opportunity to take part in some interviews to discuss their Facebook use further. The intention was to interview a selection of students who were identified as at-risk and not at-risk for depression on how they view Facebook, and how and why they use it. Interviews were conducted by the second-named author, an experienced counsellor. Interviews tended to be approximately 60 minutes in duration and were audio-recorded with permission for later verbatim transcription.

\subsection{Data Analyses}

This study used a sequential explanatory design in which quantitative data were collected before qualitative data [36]. With regard to the quantitative analysis, it is important to highlight that much of the data on Facebook is count data [37]. By definition, count variables take on only positive integer values or zero $(0,1,2)$ with a distribution that tends to be positively skewed [38]. These variables violate the statistical assumptions of normality and homoscedasticity and thus are inappropriate for parametric tests. Although one solution is to transform count data, an alternative solution adopted in this study is to use the non-parametric Mann-Whitney test [39] to determine whether there were significant differences in Facebook usage variables between students identified as at-risk for depression and those identified as not at-risk. For the qualitative analysis, a general qualitative framework using thematic analysis [40] was employed to examine the interview transcripts. Transcripts were read repeatedly and organised into meaningful categories. These extracts were then initially coded for patterns or potential themes, and then further broken down into sub-themes. Following this, the themes were then reviewed by an external reader for validity purposes.

\section{Results}

Data were analysed using SPSS Version 19.0. Prior to analysis, data were screened for missing values, outliers and out of range values. Frequencies and descriptive statistics were generated for each of the variables and a random sample of $10 \%$ of participants checked for data entry errors. Descriptive statistics for the depression scores from the DASS revealed over $50 \%$ of the students were in the Normal Range. However, $14.2 \%$ and $10.6 \%$ were classified in the Severe and Extremely Severe Ranges respectively, totalling around 25\% who were deemed to be at-risk for depression. The means and standard deviations for the selected Facebook variables for at-risk and not at-risk students can be seen in Table 1.

For students who did not present as at-risk for depression the median time spent using Facebook was 99 minutes, with Messages (26.3\%) and Photos (24.2\%) the most preferred functions on Facebook for this group. Over half reported that they used Facebook to communicate with their friends (56.6\%), with 17.2\% suggesting that Facebook allowed them to communicate with people from their past. In contrast, for at-risk students, the median time spent using Facebook per day was 105 minutes. Messages (45.7\%), the Wall (20\%) and Events (20\%) were the most preferred functions. Moreover, 46\% used Facebook to communicate with friends, though 14.3\% used it for a distraction. However, Mann-Whitney tests did not show any significant median differences in time spent online $(p=0.383)$, number of logins $(p=0.994)$ and number of friends $(p=0.494)$ between at-risk and not 
at-risk students.

Although students identified as at-risk for depression were invited and initially volunteered to participate in the interviews, none of these participants responded to subsequent emails or phone calls to organise a time to be interviewed. This is of itself an important finding where $0 / 5$ of the at-risk participants who initially volunteered for interviews followed through as participants, compared with $4 / 5$ of the not-at-risk participants. Results of the thematic analysis are presented for these not-at-risk students, for whom four themes were identified (see Table 2).

Table 1. Medians and standard deviations for time spent per day, number of logins per day and number of friends for students at-risk and not at-risk for depression.

\begin{tabular}{|c|c|c|c|}
\hline & \multicolumn{3}{|c|}{ Depression } \\
\hline & Overall & $\begin{array}{l}\text { At-risk } \\
(n=35)\end{array}$ & $\begin{array}{c}\text { Not at-risk } \\
(n=100)\end{array}$ \\
\hline Time spent per day in minutes & $\begin{array}{c}101.00 \\
(134.91)\end{array}$ & $\begin{array}{c}105.94 \\
(146.78)\end{array}$ & $\begin{array}{c}99.27 \\
(131.26)\end{array}$ \\
\hline Number of logins per day & $\begin{array}{c}6.73 \\
(7.31)\end{array}$ & $\begin{array}{c}6.71 \\
(6.05)\end{array}$ & $\begin{array}{c}6.74 \\
(7.73)\end{array}$ \\
\hline Number of friends & $\begin{array}{c}405.08 \\
(309.93)\end{array}$ & $\begin{array}{c}319.43 \\
(170.89)\end{array}$ & $\begin{array}{c}435.36 \\
(340.93)\end{array}$ \\
\hline
\end{tabular}

$\mathrm{N}=135$. Note: Standard deviations are provided in brackets.

Table 2. Examples of themes emerging from focus groups.

Themes Examples $\quad$ Exal

\section{Peer pressure to join Facebook}

Facebook as an escape

Facebook offers relief from boredom

Facebook offers distraction from unpleasant tasks

They wore me down...all my friends just kept bugging me to use Facebook and so I just kind of gave up in the end. (Participant 3)

My friends kept asking me to join. They said, “It’s great. We can talk to each other and keep in touch.” At that time, I was young and I felt like I was kind of pushed into joining. (Participant 4)

...like sometimes if I'm just waiting around or sitting around doing nothing, I get bored and it gives me something to do. (Participant 1)

Facebook is a way for me to have like a break, between studying and like procrastinating if I'm not into what I'm doing. ....when I think about it, I think that I probably use it more as a distraction from stuff that I know I need to do, but I just don't want to. (Participant 2)

Well, it's depressing that they're using Facebook as a source of constant entertainment and I don't want to be like that. (Participant 2)

...if I'm in a lecture or something, I can see students with their phones down beneath the desk and they're checking Facebook all the time instead of listening to the lecture and it bothers me. Things like that bother me. I'm not like that. (Participant 4)

\section{Critical of other users}

Excessive users referred to in derogatory terms

Poor behavior of others on Facebook There is something wrong with people who share too much personal information on Facebook ...they get really bitchy (on Facebook)... Like the practice of trolling and finding things to complain about or like, harass them about stuff they've said on Facebook constantly. (Participant 3)

I've got one friend who...she's got a lot of content that's a bit attacking and she does label people. I never get involved in it, but I feel that if I "delete” her, I'll then be the victim of her wrath, so it's

le kind of like, "Better the devil you know." I'll keep her as a friend, rather than delete her and end up as the victim in the end. (Participant 1)

I have friends that put everything that happens to them on Facebook, like if they buy something new or if they are eating something, like everything they do, they put on Facebook and I don't think that's right. (Participant 4)

...I have this one friend who has like all her photos and all her messages available to everybody and that seems pretty extreme to me. I'd never be that person, ever. (Participant 1 )

I don't like that there's stuff that people find out through the grapevine. I would describe that like, a little bit about Facebook would be like that "high school culture" like gossiping about other people, like, that's kind of rife on Facebook. (Participant 1)

Cynicism towards Facebook Facebook is an environment for socially dangerous gossip ...something that I don't like about Facebook is that it kind of seems like they keep track of what you do...like there are certain ads that seem to come up as a result of what I've put on there or something...it kind of creeps me out. (Participant 2)

Suspicious of what Facebook may do with their individual information. ...people always ask you for information; like your date of birth, what school do you go to? Things like that, and you never know what they might do with that information. Like maybe they could sell your information or something like that. (Participant 4) 


\subsection{Theme 1: Peer Pressure to Join Facebook}

Three participants indicated that as more and more of their friends joined the site, the pressure grew for them to also participate.

\subsection{Theme 2: Facebook as an Escape}

Facebook provided users with something to do when they were not satisfied with what they were actually doing in a given moment. Two sub-themes were that Facebook offered relief from boredom, and that Facebook could provide a welcome distraction from an unpleasant task.

\subsection{Theme 3: Critical of Other Users}

Three participants reported negative attitudes towards people who spend a lot of time on Facebook. A sub-theme to emerge was that participants did not wish to be like the people who they perceived were excessive Facebook users, and that excessive users were seen as somehow different and often referred to in derogatory terms. A second sub-theme referred to the poor behavior of others on Facebook, where there was a sense that one needed to be cautious and carefully manage one's online presence in order to avoid these dangers. A third sub-theme to be identified was the perception that there is something wrong with people who share too much personal information on Facebook, with three participants expressing negative views about people who reveal too much personal information on Facebook.

\subsection{Theme 4: Cynicism toward Facebook}

There was a general scepticism towards Facebook across all of the interviews. For instance, one sub-theme to emerge referred to Facebook as an environment that could be dangerous in a social sense, such as becoming the subject of gossip. A second sub-theme revealed that participants were suspicious of what Facebook may do with their individual information. It became apparent during the analysis phase that three of the four interviewees revised their initial estimate of time spent online as a result of being questioned; the fourth participant reported using it infrequently both in questionnaire data and in interview. A follow-up comparison of the quantitative and qualitative data revealed substantial discrepancies between self-reported Facebook use from the online questionnaire and that uncovered from the face-to-face interview. As can be seen in Table 3, the time spent online that participants specified on the online questionnaire was an underestimation compared with that uncovered during the interview. In other words, after the interviewer paraphrased, probed and asked for a specific breakdown of their time spent online, the participants reported spending more time on Facebook than their initial self-reports.

\section{Discussion}

The findings from this study revealed that approximately one quarter of the university students in this sample were classified by self-reported questionnaire data as being at-risk for depression, which is consistent with the findings of previous research [5]. This implies that university students are a vulnerable cohort who may find it difficult to cope with the different stressors encountered during this time. A mixed-methods approach was used to investigate whether there are differences in Facebook use between students whose self-report questionnaire data indicates that they are at-risk for depression versus those not at-risk, with a view to using this information in covert diagnosis of depression. No statistically significant differences were found in time spent on Facebook, number of logins on Facebook and number of Facebook friends between the two groups. While the majority of not at-risk participants volunteering to participate in interviews actually did so, no participants identified as being at-risk for depression actually made a time to take part in the interviews, and this finding may well be a direct manifestation of depressive symptomatology.

Analysis of data collected from not at-risk students revealed four themes with respect to Facebook: 1) peer pressure to join Facebook; 2) Facebook as an escape; 3) criticism of other Facebook users; and 4) cynicism toward Facebook. These themes suggest that participants make an effort to manage their online image in a way that distances the information on Facebook from being a reflection of their true thoughts and feelings. Although it was not possible to compare themes between at-risk and not at-risk participants, a comparison of the quantitative and qualitative data for the not at-risk interviewees revealed substantial discrepancies between self-reported 
Table 3. A comparison of time spent online responses reported on the online questionnaire and during the interview.

\begin{tabular}{ccc}
\hline & $\begin{array}{c}\text { Time spent online reported during } \\
\text { the online questionnaire }\end{array}$ & $\begin{array}{c}\text { Time spent online uncovered } \\
\text { during the interview } \\
\text { (in minutes) }\end{array}$ \\
\hline Participant 1 & 60 & 90 \\
Participant 2 & 10 & 20 \\
Participant 3 & 120 & 180 \\
\hline
\end{tabular}

questionnaire data and data obtained during an interview regarding the amount of time spent on Facebook by as much as 60 minutes per day. These data suggest caution in interpreting the predominantly self-reported questionnaire data in other studies. In the context of this study examining the possibility of diagnosing depressive symptomatology from patterns of Facebook use, it is important to note that self-report data are not accurate, and that Facebook self-disclosure is carefully self-monitored. There was also a substantial discrepancy in data regarding willingness to participate in interviews compared with actual interview participation for those identified as at-risk of depression. This lack of congruence between intention to act and subsequent action does not augur well for participation in interventions aimed at this population.

It is important to note that, with respect to the main research question of the study, no significant differences were found in the Facebook usage variables between those students identified as at-risk and not at-risk for depression. Although this was surprising at first, from the interviews it appears that changes in the pattern of Facebook usage may be more important than actual usage patterns themselves. For example, if a person who is usually Facebook-active suddenly stops their activity, or the content of status updates are not consistent with previous updates, this may indicate a possible change in mood. In other words, attention seeking or cries for help can only be recognised on Facebook in the context of knowing a typical pattern of Facebook use for the individual in question. Hence, while Moreno and colleagues [30] [31] argue that Facebook status updates might provide a novel way of diagnosing depression in young adults, the findings from this study suggest extreme caution in using Facebook or other social media for covert diagnosis, particularly without sufficient contextual information with respect to patterns of Facebook use over time. Furthermore Moreno et al. appear to assume that Facebook status updates are equivalent to actual utterances of the individual, whereas anecdotal evidence suggests that many statuses are song lyrics, movie quotes, or other internet memes shared between in-groups, which should not be taken at face value in terms of diagnostic criteria reflecting the immediate emotional state of the individual posting the status.

Given that university students frequently report communicating with friends and spending time viewing the profiles of others as reasons for using Facebook [17], the themes emerging from interview data are not surprising. However, a particularly interesting theme in terms of our current study was the criticism of other Facebook users. That is, participants revealed a negative attitude towards others who were believed to be using Facebook too much. A possible explanation for this refers to out-group differentiation [41], in which users do not want to be considered similar to excessive users who they attribute as having nothing of significant meaning in their lives and therefore depend on Facebook. Furthermore, the scepticism of Facebook found in this study is indirectly supported by research on privacy settings and Facebook in which information control and privacy are considered important to students [42]. It should also be noted that increased control over privacy settings on Facebook reduces its potential for covert mental health screening through publically available information.

A limitation of this study was the non-participation in interviews of those whose self-report questionnaire indicated that they were at-risk for depression, despite the fact that they had volunteered to be interviewed. The entire group of students whose questionnaire data indicated that they were at-risk for depression, and who volunteered to be interviewed, failed to reply to emails to arrange the interview time. None replied saying they could not schedule an appointment; they avoided any reply whatsoever. A related implication of this lack of response is that even if individuals were to be identified as at-risk for depression via their online behaviour, how would treatment be initiated and maintained? Indeed the whole notion of covert diagnosis through online behaviour is complex and ethically challenging: it is rife with implications regarding the personal boundaries and right-of-privacy for at-risk individuals, irrespective of the good intentions of the proponents.

The findings from this study suggest caution when interpreting self-report data on Facebook use, and particular caution in conceptualising particular patterns of Facebook use as representative of an individual's emotional 
well-being without knowledge of context and history both online and offline. It would be difficult to report with any accuracy associations between depression and Facebook use without having a thorough, personal understanding of the individual whose online data are being analysed. Most importantly, based on the failure of those identified as at-risk for depression to participate in the interviews, we need to consider how we can engage these at-risk students to seek out and access appropriate support services once identified, and in fact this problem is inherent in the diagnosis and has always been the major impediment to good mental health care for people with depressive symptomatology.

\section{Acknowledgements}

This research was supported by a grant from the Barbara Dicker Brain Sciences Foundation.

\section{References}

[1] Field, T., Diego, M., Pelaez, M., et al. (2012) Depression and Related Problems in University Students. College Student Journal, 46, 193-202.

[2] Hunt, J. and Eisenberg, D. (2010) Mental Health Problems and Help-Seeking Behavior among College Students. Journal of Adolescent Health, 46, 3-10. http://dx.doi.org/10.1016/j.jadohealth.2009.08.008

[3] Alloy, L.B., Abramson, L.Y., Smith, J.M., et al. (2006) Role of Parenting and Maltreatment Histories in Unipolar and Bipolar Mood Disorders: Mediation by Cognitive Vulnerability to Depression. Clinical Child and Family Psychology Review, 9, 23-64. http://dx.doi.org/10.1007/s10567-006-0002-4

[4] Andrews, B.M. and Wilding, J.M. (2004) The Relation of Depression and Anxiety to Life-Stress and Achievement in Students. British Journal of Psychology, 95, 509-521. http://dx.doi.org/10.1348/0007126042369802

[5] Bayram, N. and Bilgel, N. (2008) The Prevalence and Socio-Demographic Correlations of Depression, Anxiety and Stress among a Group of University Students. Social Psychiatry and Psychiatric Epidemiology, 43, 667-672. http://dx.doi.org/10.1007/s00127-008-0345-X

[6] Bitsika, V., Sharpley, C.F. and Hartley, L. (2010) The Specific Environmental Antecedents of Anxiety and Depression among Australian University Students: Development of the Effects of University Study on Lifestyle Questionnaire. The International Journal of Educational and Psychological Assessment, 42, 2-18.

[7] Khawaja, N.G. and Duncanson, K. (2008) Using the University Student Depression Inventory to Investigate the Effect of Demographic Variables on Students’ Depression. Australian Journal of Guidance and Counselling, 18, 195-209. http://dx.doi.org/10.1375/ajgc.18.2.195

[8] Steptoe, A., Tsuda, A., Tanaka, Y. and Wardle, J. (2007) Depressive Symptoms, Socio-Economic Background, Sense of Control, and Cultural Factors in University Students from 23 Countries. International Journal of Behavioral Medicine, 14, 97-107. http://dx.doi.org/10.1007/BF03004175

[9] Vázquez, F. and Blanco, V. (2008) Prevalence of DSM-IV Major Depression among Spanish University Students. The Journal of American College Health, 57, 165-172. http://dx.doi.org/10.3200/JACH.57.2.165-172

[10] Deroma, V.M., Leach, J.B. and Leverett, J.P. (2009) The Relationship between Depression and College Academic Performance. College Student Journal, 43, 325-334.

[11] Keyes, C.S., Eisenberg, D., Perry, G.S., et al. (2012) The Relationship of Level of Positive Mental Health with Current Mental Disorders in Predicting Suicidal Behavior and Academic Impairment in College Students. The Journal of American College Health, 60, 126-133. http://dx.doi.org/10.1080/07448481.2011.608393

[12] Liem, J., Lustig, K. and Dillon, C. (2010) Depressive Symptoms and Life Satisfaction among Emerging Adults: A Comparison of High School Dropouts and Graduates. Journal of Adult Development, 17, 33-43. http://dx.doi.org/10.1007/s10804-009-9076-9

[13] Monahan, C.J., Bracken-Minor, K.L., McCausland, C.M., et al. (2012) Health-Related Quality of Life among HeavyDrinking College Students. American Journal of Health Behavior, 36, 289-299. http://dx.doi.org/10.5993/AJHB.36.3.1

[14] Gollust, S., Eisenberg, D. and Golberstein, E. (2008) Prevalence and Correlates of Self-Injury among University Students. The Journal of American College Health, 56, 491-498. http://dx.doi.org/10.3200/JACH.56.5.491-498

[15] Garlow, S.J., Rosenberg, J., Moore, J.D., et al. (2008) Depression, Desperation, and Suicidal Ideation in College Students: Results from the American Foundation for Suicide Prevention College Screening Project at Emory University. Depression and Anxiety, 25, 482-488. http://dx.doi.org/10.1002/da.20321

[16] Cheung, C.M.K., Chiu, P. and Lee, M.K.O. (2010) Online Social Networks: Why Do Students Use Facebook? Computers in Human Behaviour, 27, 1337-1343. http://dx.doi.org/10.1016/j.chb.2010.07.028

[17] Pempek, T.A., Yermolayeva, Y.A. and Calvert, S.L. (2009) College Students' Social Networking Experiences on 
Facebook. Journal of Applied Developmental Psychology, 30, 227-238. http://dx.doi.org/10.1016/j.appdev.2008.12.010

[18] Amichai-Hamburger, Y. and Ben-Artzi, E. (2003) Loneliness and Internet Use. Computers in Human Behaviour, 19, 71-80. http://dx.doi.org/10.1016/S0747-5632(02)00014-6

[19] Correa, T., Willard Hinsley, A. and de Zuniga, H.G. (2010) Who Interacts on the Web? The Intersection of Users' Personality and Social Media Use. Computers in Human Behaviour, 26, 247-253. http://dx.doi.org/10.1016/j.chb.2009.09.003

[20] Ross, C., Orr, E.S., Sisic, M., et al. (2009) Personality and Motivations Associated with Facebook Use. Computers in Human Behaviour, 25, 578-586. http://dx.doi.org/10.1016/j.chb.2008.12.024

[21] Ryan, T. and Xenos, S. (2011) Who Use Facebook? An Investigation into the Relationship between the "Big Five", Shyness, Narcissism, Loneliness, and Facebook Usage. Computers in Human Behaviour, 27, 1658-1664. http://dx.doi.org/10.1016/j.chb.2011.02.004

[22] Wilson, K., Fornasier, S. and White, K.M. (2010) Psychological Predictors of Young Adults' Use of Social Networking Sites. Cyberpsychology, Behaviour and Social Networking, 13, 173-177. http://dx.doi.org/10.1089/cyber.2009.0094

[23] Ellison, N.B., Steinfield, C. and Lampe, C. (2007) The Benefits of Facebook "Friends": Social Capital and College Students Use of Online Social Network Sites. Journal of Computer-Mediated Communication, 12, 1143-1168. http://dx.doi.org/10.1111/j.1083-6101.2007.00367.x

[24] Kalpidou, M., Costin, D. and Morris, J. (2011) The Relationship between Facebook and the Well-Being of Undergraduate College Students. Cyberpsychology, Behaviour and Social Networking, 14, 183-189. http://dx.doi.org/10.1089/cyber.2010.0061

[25] Mehdizadeh, S. (2010) Self-Presentation 2.0: Narcissism and Self-Esteem on Facebook. Cyberpsychology, Behavior, and Social Networking, 13, 357-363. http://dx.doi.org/10.1089/cyber.2009.0257

[26] Kraut, R., Patterson, M., Lundmark, V., et al. (1998) Internet Paradox: A Social Technology That Reduces Social Involvement and Psychological Well-Being? American Psychologist, 53, 1017-1031. http://dx.doi.org/10.1037/0003-066X.53.9.1017

[27] Buffardi, L.E. and Campbell, W.K. (2008) Narcissism and Social Networking Sites. Personality and Social Psychology Bulletin, 34, 1303-1314. http://dx.doi.org/10.1177/0146167208320061

[28] Pantic, I., Damjanovic, A., Todorovic, J., et al. (2012) Association between Online Social Networking and Depression in High School Students: Behavioural Physiology Viewpoint. Psychiatria Danubina, 24, 90-93.

[29] Rosen, L.D., Whaling, K., Rab, S., et al. (2013) Is Facebook Creating “iDisorders”? The Link between Clinical Symptoms of Psychiatric Disorders and Technology Use, Attitudes and Anxiety. Computers in Human Behaviour, 29, 1243-1254. http://dx.doi.org/10.1016/j.chb.2012.11.012

[30] Moreno, M., Jelenchick, L.A. and Egan, K.G. (2011) Feeling Bad on Facebook: Depression Disclosures by College Students on a Social Networking Site. Depress Anxiety, 28, 447-455. http://dx.doi.org/10.1002/da.20805

[31] Moreno, M.A., Christakis, D.A., Egan, K.G., Jelenchick, L.A., Cox, E., Young, H., Villiard, H. and Becker, T. (2012) A Pilot Evaluation of Associations between Displayed Depression References on Facebook and Self-Reported Depression Using a Clinical Scale. Journal of Behavioral Health Services \& Research, 39, 295-304. http://dx.doi.org/10.1007/s11414-011-9258-7

[32] Association, A.P. (2000) Diagnostic and Statistical Manual of Mental Disorders. American Psychiatric Association, Washington DC.

[33] Kline, T.J.B. (2005) Psychological Testing: A Practical Approach to Design and Evaluation. Sage Publications, Thousand Oaks, CA.

[34] ObjectPlanet Inc. (2011) Opinio 6.5 [Computer Software]. Oslo.

[35] Lovibond, P.F. and Lovibond, S.H. (1995) The Structure of Negative Emotional States: Comparison of the Depression Anxiety Stress Scales (DASS) with the Beck Depression and Anxiety Inventories. Behaviour Research and Therapy, 33, 335-343. http://dx.doi.org/10.1016/0005-7967(94)00075-U

[36] Hanson, W.E., Creswell, J.W., Clark, V.L.P., Petska, K.S. and Creswell, J.D. (2005) Mixed Methods Research Designs in Counseling Psychology. Journal of Counseling Psychology, 52, 224-235. http://dx.doi.org/10.1037/0022-0167.52.2.224

[37] Skues, J.L., Williams, B. and Wise, L. (2012) The Effects of Personality Traits, Self-Esteem, Loneliness, and Narcissism on Facebook Use among University Students. Computers in Human Behavior, 28, 2414-1419. http://dx.doi.org/10.1016/j.chb.2012.07.012

[38] Coxe, S., West, S.G. and Aiken, L.S. (2009) The Analysis of Count Data: A Gentle Introduction to Poisson Regression and Its Alternatives. Journal of Personality Assessment, 91, 121-136. http://dx.doi.org/10.1080/00223890802634175

[39] Field, A. (2005) Discovering Statistics Using SPSS. 2nd Edition, Sage Publications, Thousand Oaks. 
[40] Braun, V. and Clarke, V. (2006) Using Thematic Analysis in Psychology. Qualitative Research in Psychology, 3, 77101. http://dx.doi.org/10.1191/1478088706qp063oa

[41] Turner, J.C. (1982) Towards a Cognitive Redefinition of the Social Group. In: Tajfel, H., Ed., Social Identity and Intergroup Relations, Cambridge University Press, Cambridge, 15-40.

[42] Christofides, E., Muise, A. and Desmarais, S. (2009) Information Disclosure and Control on Facebook: Are They Two Sides of the Same Coin or Two Different Processes? Cyberpsychology and Behaviour, 12, 341-345.

http://dx.doi.org/10.1089/cpb.2008.0226 
Scientific Research Publishing (SCIRP) is one of the largest Open Access journal publishers. It is currently publishing more than 200 open access, online, peer-reviewed journals covering a wide range of academic disciplines. SCIRP serves the worldwide academic communities and contributes to the progress and application of science with its publication.

Other selected journals from SCIRP are listed as below. Submit your manuscript to us via either submit@scirp.org or Online Submission Portal.
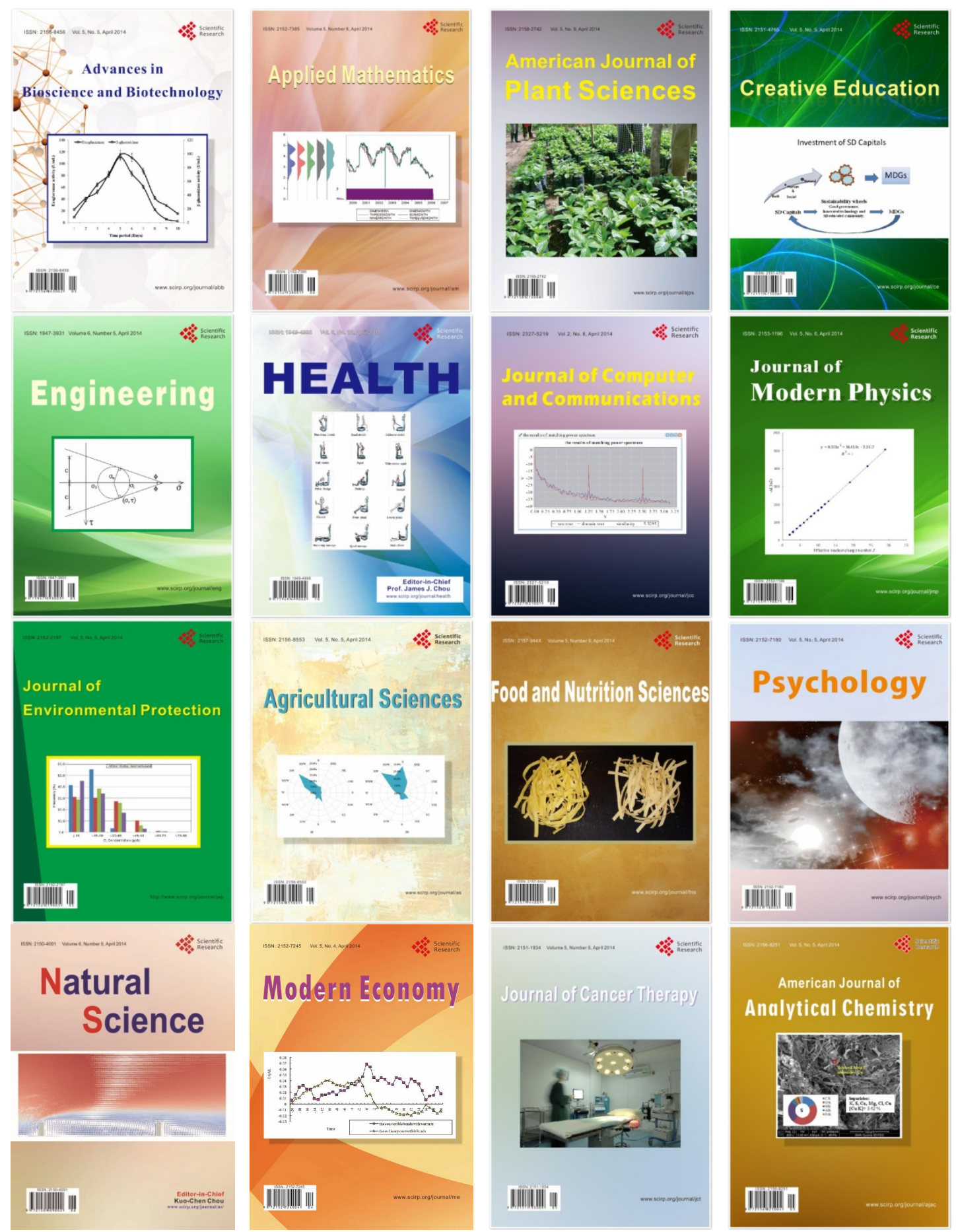